\title{
DEFINIENDO UNA ANTROPOLOGÍA PARA EL CRIMINAL EN EL CHILE FINISECULAR (SIGLOS XIX-XX)
}

Defining an anthropology for criminals at the turn of the century Chile $\left(X I X-X X\right.$ centuries $^{l}$

\author{
Marco Antonio León León*
}

Resumen

Este estudio busca rescatar el papel del pensamiento antropológico criminal en Chile en la construcción de una nueva imagen del criminal urbano. En tal sentido, se argumenta que las ideas de Lombroso y Bertillón habrían otorgado un respaldo "científico" a prejuicios que estigmatizaban a grupos específicos de la población en las ciudades, como eran los sectores populares. Igualmente, en un período cronológico que abarca desde fines del siglo XIX hasta mediados de la centuria siguiente se puede apreciar cómo los planteamientos centrales de este nuevo saber criminológico habrían ayudado a justificar los criterios y medidas de las autoridades, tendientes a definir una política de defensa social basada en la caracterización de un "enemigo común", identificable ahora a partir de un registro fotográfico que retrataba asimismo su malsana naturaleza interior, como también por determinados rasgos físicos que revelaban su predisposición biológica al mal.

Palabras clave: Antropología criminal, Antropometría, Bertillonage, Criminología, Identificación.

Abstract

This study seeks to analyze the role of the anthropological depiction of crime in Chile for the construction of a new image of the urban criminal. Accordingly, it is argued that notions of Bertillon and Lombroso would have given "scientific" support to prejudices that stigmatized specific population groups in the popular sectors of the cities. Also, in a chronological period from the end of the 19th century until the middle of the next century, we can see how the main ideas of this new criminological approaches would have helped to justify the criteria and measures taken by the authorities to define a social defense policy based on the characterization of a "common enemy". This was now identifiable from a photographic record that depicted his unhealthy inner nature, as well as certain physical features that revealed his biological predisposition to evil.

Key words: Criminal anthropology, Anthropometry, Bertillonage, Criminology, Identification.

\section{INTRODUCCIÓN}

Las ideas penales surgidas de la modernidad ilustrada intentaron desde temprano no solo disminuir los actos delictivos, sino además tratar de entender las causas que le daban sentido y proyección a los crímenes en ciudades y zonas rurales

\footnotetext{
${ }^{1}$ Este trabajo forma parte del Proyecto Fondecyt No 1140777 (2014-2016).
} 
(Anitua, 13-32), Paulatinamente se comenzó a plantear la necesidad de estudiar al criminal, pues al hacerlo se desentrañaban sus intenciones y se podía, idealmente, desincentivar sus acciones futuras. Fue allí donde partió una nueva concepción de cómo debía enfrentarse el delito y el crimen, el delincuente y el criminal; apelando ya no solo a la sanción o represión de conductas, sino también a la posibilidad de acabar con ellas, de enmendarlas o regenerarlas, que fue el término que logró más aceptación a medida que avanzó el siglo XIX. Por supuesto, si se toma en cuenta el desarrollo de estas ideas y propuestas, que iban unidas al filantropismo de los ilustrados y a quienes deseaban reformar el carácter y organización de las prisiones, es posible darse cuenta que se iniciaba una nueva disciplina acerca del tema, la que encontró acogida entre sus contemporáneos, aunque fue conceptualizada varias décadas más tarde. Nos referimos en concreto a la criminología, saber abocado al estudio del crimen y el criminal que en una primera etapa, desde mediados del siglo XVIII y hasta la primera mitad del XIX, estuvo centrada en el libre albedrío y en la necesidad de establecer una proporción entre las penas y los delitos cometidos. Dicha mirada al mundo del crimen y de los criminales fue denominada como clásica para contraponerla al desarrollo y posterior consolidación de otra mirada criminológica avanzada la centuria decimonónica, caracterizada como positivista, por la influencia de las ideas de Auguste Comte en ella, aunque involucrara planteamientos antropológicos, evolucionistas y raciales definidos previamente.

Con los aportes de la criminología positivista la política criminal, encaminada a la defensa social desde mediados de la centuria decimonónica, logró un respaldo más "digno" y "respetable" ante la colectividad, pues ya no se basó en simples prejuicios relativos a determinados grupos sociales, sino que ahora encontró en la ciencia un soporte para justificar sus diversas acciones y argumentos (Becker y Wetzell, 2006). Al negar toda racionalidad a los comportamientos de sujetos y colectividades específicas, tildados como anormales, aumentó la distancia entre el hombre normal, obediente y trabajador, respecto de aquellos que atacaban el orden político y legal, legitimándose así las medidas radicales en el tratamiento de la delincuencia y de los grupos considerados peligrosos (Del Olmo, 28-31). Así se fue gestando un cambio en la construcción antropológica del sujeto criminal, que en la perspectiva de la criminología clásica podía involucrar a cualquier persona que, en el uso de su libre albedrío, terminaba transgrediendo la normatividad por diversas razones, que iban desde lo personal, pasando por lo social, hasta lo sicológico. El determinismo de la criminología positivista, en cambio, o de la antropología criminal como también se le denominó, redefinió a ese sujeto criminal, respaldando el conjunto de aprehensiones que tanto las autoridades políticas-gubernativas como las elites urbanas tenían respecto de los sectores populares. Por ello, en no pocas oportunidades, la "cuestión social" que caracterizó al período de tránsito desde el siglo XIX al XX en Chile, se vinculó igualmente a una "cuestión criminal", lo que encontraría proyecciones en las décadas siguientes. 


\section{EL CRIMINAL Y SU NATURALEZA}

Si existía una ciencia natural que ayudaba a comprender el mundo y sus dinámicas, debía estar presente asimismo una ciencia que se encargara de resolver o adelantar los posibles problemas que una sociedad en transición, desde lo tradicional a lo moderno, podía experimentar. La solución de dichos inconvenientes sociales y económicos se convirtió en un tema de estudio, pero más que buscar causas en la falta de políticas gubernamentales o en la gestión de las autoridades locales, se visualizaron como responsables a determinados grupos urbanos, marcados por su pobreza y marginación de lo que se entendía en el siglo XIX por una vida "civilizada". Esos eran los sectores populares, cuyos comportamientos habían sido cuestionados desde hacía siglos, pero que ahora se veían, por su proclividad, a caer en vicios que derivaban en delitos, como sujetos-objetos de una ciencia que debía concentrarse en ellos, analizarlos, clasificarlos y, de ser posible, regenerarlos. Esa fue la lógica que estuvo detrás del nacimiento de la antropología criminal como un saber de identificación, diagnóstico y experimentación, cuya principal materia prima eran los delincuentes y criminales surgidos del bajo pueblo urbano.

Esta nueva forma de conocimiento fue usada como una disciplina indicativa para individualizar a los potenciales agresores de la propiedad, a los socialmente peligrosos. Se ofreció así como un saber práctico (una pedagogía) necesaria a la política de prevención y represión de los criminales y fue utilizada, en distintos niveles, por jueces y policías. Por supuesto, detrás de dicha política de defensa social se encontró el miedo social que tampoco era nuevo, pero que igualmente tuvo renovadas formas. El crecimiento urbano y la industrialización habían generado una nueva marginalidad, la de los grupos proletarios, a quienes se les asociaba con una peligrosidad derivada del propio desarrollo económico capitalista que provocaba desigualdades en la distribución de la riqueza. De ahí el temor a que estos grupos se rebelaran y atentaran contra la vida y patrimonio de los privilegiados (Chevallier, 1978).

Se aprovechó asimismo la identidad conflictiva atribuida a los obreros (proletarios-pobres-criminales) por las elites y se intentó definir a las clases peligrosas como naturalmente distintas de las trabajadoras, atribuyendo a las primeras la cualidad de "degeneradas" y a las segundas la cualidad de "útiles". En ello cobró un papel fundamental la estadística, que cuantitativamente demostró cómo el grueso de los perpetradores de delitos provenía de los sectores sociales más bajos de la sociedad.

En consecuencia, la antropología criminal elaboró su propio marco de interpretación del delito y los delincuentes, ocupando como principio básico la utilización del método científico para probar que sus acercamientos al estudio de la criminalidad eran empíricamente verificables (León León, 2003). Esta tuvo su origen en la Italia de mediados del siglo XIX y fue concebida a partir de la disección craneal que el italiano Cesare Lombroso (1835-1909) practicara a un célebre criminal: 
Villela. Tal operación le permitió observar ciertas anomalías que lo llevaron a pensar que el delincuente presentaba atavismos antropológicos que no solo lo identificaban como tal, sino además lo vinculaban con los hombres primitivos, portadores del instinto salvaje de los animales (Peset, 154-164).

La publicación de su principal obra, El hombre delincuente, en 1876, sintetizó y consolidó dichas afirmaciones. Como sostiene una investigación reciente, en buena medida "parte de la fama decimonónica de la antropología criminal se debió al prestigio de la teoría evolutiva, y en este punto hay que señalar, sumada a la discutible interpretación que Lombroso hace de Darwin, la idea de recapitulación propuesta por el "bulldog alemán" del segundo: Ernst Haeckel. Además, desde el campo científico se generaban teorías cuyo cerrado determinismo se ajustaba perfectamente a los postulados de Lombroso" (Da Re y Maceri, 101). Las teorías de Lombroso y sus seguidores se expandieron a Italia, Inglaterra y a otros países, e inspiraron una fascinación por el lazo entre la herencia y la conducta delictiva que apasionaría a los científicos sociales al menos durante medio siglo (Herman, 124).

$\mathrm{Si}$ el estudio de los criminales era una ciencia, quienes se dedicaban o acercaban a ella eran los "nuevos profesionales" (criminólogos) de esta renovada manera de mirar la realidad delictiva. Fue así como la terminología científica empezó a adoptarse, empleándose conceptos como los de "patología social", "enfermedad", "contagio", "laboratorio", "actividad terapéutica"; solo por mencionar a los más conocidos. De acuerdo con el "diagnóstico" de Lombroso, los criminales tenían una condición atávica que venía en su carga hereditaria, condición que luego extrapolaba a los pueblos no europeos los que, a su entender, "eran menos evolucionados" colocándolos "en el lugar casi de ancestros de la humanidad, para luego igualarlos con los criminales" (Da Re y Maceri, 111). Si bien la antropología criminal había surgido desde la medicina, su impacto fue mayor en el derecho, en especial al momento de explicar las desigualdades sociales y las transgresiones a la ley. Institucionalmente se apoyó en el régimen penitenciario que había logrado consolidación en EE.UU., Europa y América Latina décadas antes (Salvatore y Aguirre, 1996; Buffington, 2001; Piccato, City of suspects); creándose espacios controlados e ideales para que los criminólogos desarrollaran su tarea de identificación, así como de clasificación y estudio de los delincuentes.

Este saber criminológico no estuvo vinculado a un proyecto político específico, pues fue asimilado por conservadores, liberales y hasta por el socialismo. La responsabilidad moral, defendida hasta entonces por la criminología clásica, fue reemplazada por una elevada dosis de determinismo, junto con un nuevo enfoque terapéutico de la vida social. Esta nueva postura tuvo también como bandera de lucha la reforma de los recintos carcelarios, los que ya no solo debían velar por la privación de libertad en condiciones dignas, con instrucción y trabajo en talleres, sino además encargarse de clasificar e incorporar a la población penal a los estudios de los criminólogos. De allí que en la generación de conocimiento criminal se concibiera a 
las prisiones como "laboratorios" desde donde era posible llevar a cabo dicha tarea (Salvatore y Aguirre, 169-193; Salvatore, 127-158)2. Con este mismo criterio, la primera publicación chilena que dio cabida oficial a estas ideas, la Revista de Prisiones, dependiente de la Dirección General de Prisiones (1889-1896), aclaraba en uno de sus artículos que:

La escuela criminal positiva tiene por objeto, en el campo práctico, la disminución de los delitos; en el teórico, se propone el estudio concreto del delito como hecho natural y por eso es que estudia a quien comete el delito: al hombre delincuente [...] El criminalista como el médico de aquella antigua escuela, ha debido ocuparse del delincuente como del enfermo. No basta curar al delito sino al delincuente y he ahí lo que busca y pretende la escuela positivista, que se levanta contra las teorías de la escuela clásica (Revista de Prisiones $\mathrm{N}^{\circ} 1$ 1889: 45-46).

Los problemas de esta "ciencia del criminal" era que trataba de convertir los supuestos en verdades, o las hipótesis en certezas, pues partía de la base de que los criminales respondían a causas similares, olvidando contextos geográficos, sociales y familiares. Muchas de sus conclusiones provenían de los delincuentes encarcelados que se prestaban con facilidad para sus indagaciones, lo que significaba fundar gran parte de sus argumentos y conclusiones en la equiparación entre delincuentes y reos, afectando con ello a los futuros diagnósticos y predisponiendo a los criminólogos para asociar conductas similares a medios o escenarios disímiles. La realidad, vista así, era obvia: el encarcelado era el "conejillo de indias", mientras el observador era el "científico" y la cárcel el "laboratorio social".

\section{LA ANTROPOLOGÍA CRIMINAL COMO “CIENCIA DE OBSERVACIÓN”}

La criminología comenzó a darle un rostro al criminal, un carácter concreto, pues era posible examinarlo, describirlo y hasta medirlo. Dejó de ser un ente abstracto para convertirse en un referente de lo inadecuado y lo grotesco, idea que, gracias a la invención y masificación de la fotografía desde mediados del siglo XIX, pudo ahora ser explicitada y difundida por los diversos medios de prensa que paulatinamente comenzaron a abandonar los grabados y dibujos y a incorporar fotografias a sus ediciones. Este saber se enriqueció, circuló y se volvió más complejo, a la par de retomar los prejuicios ya existentes acerca de los grupos bajos. Le entregó un soporte "científico" a prejuicios que no eran nuevos y que incorporaban además algunas consideraciones respecto de la influencia del medio social en las conductas

\footnotetext{
${ }^{2}$ Esas fueron, entre otras, las discusiones planteadas en los Congresos de Antropología Criminal desarrollados en Roma (1885) y París (1889). Un ejemplo de la repercusión de estos planteamientos en América Latina se encuentra en Salvatore y Aguirre, 169-193; y en Salvatore, 127-158. No obstante, Salvatore confunde el discurso reformista penitenciario, muy anterior a la antropología criminal, con algunas propuestas de esta para usar las prisiones como laboratorios de investigación social-criminal.
} 
de los criminales, su falta de intelecto y de buenas costumbres; aspectos subordinados al criterio principal de que el aspecto y rasgos físicos de los mismos evidenciaban no solo su extracción social, sino además un problema más profundo: una carencia o interrupción de su etapa evolutiva (Zimmermann, 23-46; Piccato, $\mathrm{La}$ construcción, 133-181; Aguirre, 2005).

En función de lo expresado, se entiende que los criminales, o quienes se acercaban a serlo, debiesen ser identificados o registrados con más precisión. Había que describirlos, pero de una manera certera, pues ya no bastaba el reconocimiento personal, la mutilación o las marcas corporales como señas distintivas, sino que en sociedades más complejas la individualización se volvía algo complicado. De ahí la opción por la fotografia, en un principio, y después por la medición de los miembros, la descripción del color de los ojos, el perfil de la cara, la nariz, los labios, la dimensión de la frente, el mentón y cualquier otra señal que pudiera caracterizar a este sujeto-objeto de estudio.

El criminal exhibía síntomas patológicos específicos que Lombroso y sus seguidores catalogaron como propios de una conducta "antisocial", porque erosionaba la estructura y necesidades de la sociedad moderna. ¿Era posible distinguir a estos antisociales de los ciudadanos "normales"? De acuerdo con este autor, existían ciertos rasgos físicos o "estigmas" que revelaban el atavismo de un criminal nato. Entre ellos una frente baja y curva; ojos duros y evasivos; orejas grandes con forma de manija; una nariz plana o curvada hacia arriba y una mandíbula prominente; grandes incisivos medios; pies prensiles y brazos largos y simiescos; una barba escasa y calvicie. Asimismo, se decía que los ladrones tenían narices "negroides", torcidas o planas; los homicidas rectas y aguileñas y los violadores cejas pobladas. Lombroso agregaba que el criminal nato, al igual que el salvaje, era insensible al dolor y tenía tendencia a la venganza, la pereza y la traición.

Para los antropólogos criminales, el delito no podía reducirse a una definición jurídica ni tampoco se podía aceptar que fuese el producto de un acto voluntario. Existían factores que explicaban las conductas delictivas y que debían ser investigados. Tal determinismo encerraba una teoría que llegaría a cobrar aceptación con los años y que sostenía que la criminalidad tenía un fundamento natural, es decir, que el crimen era el resultado de causas bioantropológicas (Horcasitas, El determinismo biológico, 99-126). Por tal razón, contradiciendo lo sostenido por la criminología clásica, había una diferencia fundamental entre el hombre delincuente y las personas "normales":

"El profundo determinismo biológico de Lombroso le hace negar que los criminales tengan alguna posibilidad de elegir. Para él, los criminales natos delinquen obligados por su naturaleza primitiva y atávica, mientras que otro grupo lo hace empujado por factores extrabiológicos (la falta de educación, la pobreza, la marginación, etc.) y, en consecuencia, jamás pueden elegir" (Da Re y Maceri, 93). 
Los progresos obtenidos por las ciencias naturales en el siglo XIX mostraron la importancia de contar con un método científico. Entre el mundo físico y el mundo social, se suponía, existían leyes comunes y, como tales, cognoscibles por medio de un método común. Ello fue lo que llevó a una interpretación mecanicista de la sociedad. Así, a la idea de un libre albedrío se opuso un férreo determinismo biológico, pues el crimen tenía una causa antropológica anterior a cualquier definición jurídica (debido a la distinta conformación del cráneo, un cromosoma anómalo, etc.). De ahí que fuese preciso un método experimental que, basado en la experimentación y la observación, estableciera las leyes que regían el comportamiento criminal. Acto seguido vendría la clasificación de los mismos y el examen detallado de las causas de sus conductas delictivas (Blanckaert, Des savages, 70). No obstante, era complicado tratar de entender si en verdad algunos individuos (hombres, mujeres y niños) estaban predeterminados para delinquir, como tampoco era fácil explicar quiénes tenían alguna posibilidad de ser regenerados.

De acuerdo con lo planteado por Beatriz Urías Horcasitas, las teorías antropológicas referentes a las razas en México estuvieron marcadas solo marginalmente por el positivismo criminológico italiano, pues estas eran anteriores a él, junto al hecho de que tal postura fue rechazada por los círculos antropológicos (Horcasitas, Indígena y criminal, 145-166; Blanckaert, Lógicas da antropotecnia, 145-156) ${ }^{3}$. En Chile, tal panorama es menos claro, pues no hay evidencias de una aceptación o rechazo general a los planteamientos positivistas por parte de los antropólogos, quienes por lo demás, para inicios del siglo XX, estaban más preocupados por rebatir la teoría de una supuesta homogeneidad racial chilena, defendida por los cronistas coloniales y Diego Barros Arana en el siglo anterior. Tal argumentación fue descartada con fuerza por Ricardo E. Latcham desde 1911 (Orellana, 22-23) ${ }^{4}$. En lo que respecta a Lombroso y la antropología criminal, no hemos encontrado menciones, las que son más evidentes y numerosas fuera del ámbito antropológico, según veremos.

En no pocos análisis pertinentes en la materia realizados por contemporáneos, especialmente médicos y juristas, se solían combinar las dimensiones antropológicas, biológicas y sociales del problema criminal, dándose énfasis en algunas oportunidades a las condiciones de vida como determinantes de conductas delictivas:

\footnotetext{
${ }^{3}$ Según la autora, tampoco en Francia ni en Alemania el positivismo criminológico fue recibido de manera convincente por los antropólogos. En México habría ocurrido algo similar, siendo recibido solo por los juristas. Para el caso de Brasil, sabemos del anatomista Léonce Manouvrier como alguien contrario a las ideas lombrosianas (Blanckaert, Lógicas da antropotecnia, 145-156).

${ }^{4}$ Los estudios que analizan el desarrollo de la antropología en Chile en este período son, por lo general, escasos. Una visión panorámica, de donde hemos extraído la información citada, se encuentra en Orellana (22-23). Obra que, pese a su título, contempla igualmente la evolución de la disciplina antropológica.
} 
El medio social es una fuente prodigiosa de móviles más o menos fuertes que contribuyen a imprimir caracteres variados en las acciones humanas. El individuo tiene una tendencia marcada a hacer lo que ve; es esencialmente imitador. De aquí la influencia benéfica o perniciosa del ejemplo. El hombre recibe el primer germen de su individualidad posterior en el seno de su familia; y es natural pensar que el buen contacto hará individuos buenos y honrados, útiles para la sociedad en que vive; y que el mal contacto formará caracteres malignos y dará frutos podridos. Además, por la ley de la adaptación, se modelarán también organismos robustos como se modelarán espíritus bien constituidos (Vergara Flores, 356).

Así igualmente lo hacían notar otros comentaristas, mostrando que no se trataba de un juicio aislado:

La Antropolojía criminal, ciencia de observación, ha conquistado hasta hoy, aclarándolo, gran parte del oscuro, estenso e incierto terreno de la criminología; ha reducido a sus justos límites el tipo del criminal nato, $i$ ha invocado las causas sociales como necesarias, para la explicación de la criminalidad. Quédale por fijar la solución de los problemas sociales inherentes, i propender al estudio e implantación de una legislación adecuada i universal; que, preservando a la Sociedad, combata i castigue el crimen, e impida las injusticias que pueden cometerse por falta de reconocimiento oportuno de los irresponsables (Beca, 16).

[Es preciso] abrir con prudencia nuestro derecho penal, nacido de la escuela clásica, a los nuevos horizontes señalados por la escuela positiva, que desenvuelve i completa a aquella, aplicando al estudio de los delitos i de las penas el método experimental e inductivo, que ya ha dado extraordinario impulso i desarrollo a las ciencias físicas i sociales i que sustituye a las hipótesis abstractas el estudio profundo de los hechos. Debe, asimismo, establecer un equilibrio equitativo entre los derechos individuales i sociales; $i$ tener presente, en lo posible, los factores naturales del delito i las categorías antropolójicas i las condiciones sociales e intelectuales de los delincuentes i el medio en que se han formado (Ministerio de Justicia Vol. 294, 1899 en Fernández, 38).

En esta línea de razonamiento el orden social no era puesto en duda, pues, todo lo contrario, este era legitimado y las responsabilidades se buscaban en las condiciones de vida y en la natural peligrosidad del autor del delito:

...ora es la inclinación innata de defectuosa organización física i moral la que impele instintivamente al hombre a la subversión de las leyes civiles i naturales, ora la absoluta carencia e ignorancia de la moral cristiana la que ciega al padre i no ve la horrenda pendiente en que él, i por su culpa, el hijo tiene fatalmente que caer, abandonados como están a la mazmorra de los vicios i al fango pútrido de las malas compañías (Barros Ovalle, II-III). 
La criminología positivista, a pesar de reconocer en parte la influencia del ambiente social respecto del crimen, como respuesta a los procesos de urbanización, industrialización y masificación-despersonalización de los individuos (Outtes, 7-29), terminó por explicar en forma ahistórica y apolítica la criminalidad, pues partió del supuesto de que existían valores sociales determinados naturalmente. Ignoró la mayoría de las veces el estudio de los procesos sociales donde la ley penal era producida y modificada, olvidando las relaciones que unían las reacciones sociales con la criminalidad y que hacían posible que una política criminal fuese de cierta calidad y no de otra. Tal línea argumentativa ayuda a explicar que el criminólogo positivista aceptara el statu quo legal. Esto no debe extrañar si se piensa que Lombroso y sus discípulos negaban la idea de que los criminales tuvieran conciencia de sus actos delictivos (o responsabilidad moral como sostenía la criminología clásica), pues el delito, a su entender, era un fenómeno determinado por causas biológicas que en el transcurso de la evolución se transmitían de generación en generación hasta convertirse en atavismos.

Uno de los seguidores de Lombroso, Enrico Ferri (1856-1929), no solo matizó y ayudó a difundir muchas de las ideas de la antropología criminal (Rivacoba, 124-125) ${ }^{5}$, sino además mostró que tales planteamientos no estaban concebidos solo para ser incorporados por las elites liberales europeas y americanas, ya que igualmente otras ideologías progresistas como el socialismo veían en su asimilación una estrategia para depurar los vicios y mejorar la condición de vida de las clases trabajadoras. Tal situación encuentra un buen ejemplo en Chile al confirmarse la visita de Ferri al país. A poco de terminados los festejos de la celebración del centenario de la República, Ferri llegó a Santiago, vía Mendoza, desde Buenos Aires con el propósito de dictar tres conferencias en el Teatro Municipal de la ciudad (la primera de ellas repetiría luego en el Teatro Edén en Valparaíso). El diario El Mercurio de la capital, de tinte conservador, fue uno de los principales publicistas de su llegada y estadía, catalogándolo de "ilustre sociólogo y criminalista", "alumno de la cátedra científica del gran Lombroso" y de "tribuno y abogado, sociólogo y penalista" (El Mercurio, 28 de septiembre de 1910).

De acuerdo con la reconstrucción de este evento, realizada por Jaime Massardo (Massardo, 142-144), el público que recibió a Ferri, bastante heterogéneo, iba desde dirigentes de la Federación de Estudiantes de la Universidad de Chile, pasando por personajes como Malaquías Concha, dirigente del Partido Democrático, el fundador de un Partido Socialista de connotaciones positivistas (Alejandro Bustamante), el

\footnotetext{
${ }^{5}$ En la opinión de Rivacoba: "Ferri concibe aún la sociología criminal en un sentido enciclopédico, que él dice sintético, comprensivo de la Antropología, la Psicología y la Estadística criminales, del Derecho Penal y de las disciplinas penitenciarias, desdibujándose con esta amplitud y heterogeneidad su contorno y naturaleza, pero no es menos cierto que atiende en particular a los aspectos sociológicos, procurando armonizarlos con los biológicos que había estudiado Lombroso, y condensando esta posición en la siguiente frase: "El medio social, pues, da la forma al delito, que tiene su base en el factor biológico".
} 
representante del Centro Radical, y un par de diputados, entre ellos el futuro Presidente de la República, Arturo Alessandri Palma, quien quince años antes había dado en el Club del Progreso de Santiago una conferencia sobre Ferri y su obra. A juicio de Massardo, la recepción a Ferri demostraba no solo la función progresista que le atribuía al positivismo la elite dirigente de entonces, sino además cómo la esperanza de construir un mejor futuro social tenía eco en la cultura política de las clases subalternas, generándose simpatías hacia dicha corriente de pensamiento (Massardo, 144). El progreso, por tanto, podía ser asumido por conservadores, liberales y socialistas, como también se entendía que la lucha contra la criminalidad era una tarea más allá de cualquier ideología partidista. De ahí que no era extraño que tal derrotero fuese transitado tanto por quienes querían preservar un orden político y social determinado como por quienes deseaban construir uno nuevo, aunque en esencia significara igualmente una selección, organización y exclusión de seres humanos.

A dicha tarea prestaba utilidad la antropología criminal, presente en el discurso de las autoridades, en las instituciones y en las figuras de la intelectualidad de entonces (El Mercurio, 4-5 de octubre de 1910) ${ }^{6}$, como era el caso de Valentín Letelier, quien al encabezar la despedida de Ferri le habría indicado al italiano su reconocimiento dentro del medio jurídico chileno con estas palabras: "si hubieses atravesado los dinteles de nuestra Escuela de Derecho [de la Universidad de Chile], habríais podido observar que vuestro nombre se cita como la palabra del maestro" (El Mercurio, 6 de octubre de 1910). Si bien es posible pensar que no todos aceptaran íntegros los contenidos de esta corriente criminológica, existiendo disensos y contradicciones en su interpretación al igual que una integración no siempre lineal a los ámbitos de la medicina y el derecho, no puede negarse que su presencia se hizo común desde temprano en varios escritos, coronando así la visita de Ferri al país toda una etapa.

\footnotetext{
${ }^{6}$ La presencia de Ferri en Chile no solo despertó admiración, sino igualmente crítica entre algunos sectores como la Iglesia Católica. El Arzobispo de Santiago, Juan Ignacio González Eyzaguirre, solicitó a los católicos que no acudieran a las conferencias del italiano (El Mercurio, Santiago, 4 de octubre de 1910). Además, una de las conferencias relativas a la "psicología de la mujer" motivó varios cuestionamientos que se hicieron explícitos en la prensa (El Mercurio, Santiago, 5 de octubre de 1910). Ello no es algo fortuito, pues Ferri también consideraba, igual que Lombroso, la inferioridad biológica y sicológica de la mujer. Un buen ejemplo de la difusión anterior de dichos planteamientos se encuentra en el trabajo de Brandau (1908).
} 


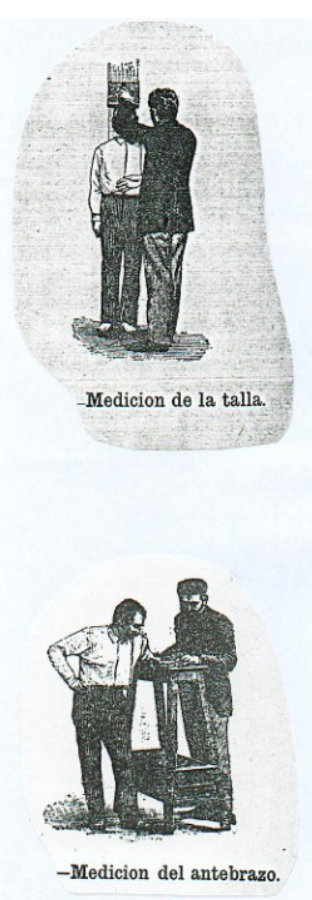

Figura 1. Mediciones de determinados rasgos físicos a los delincuentes, según la recomendación de Pedro N. Barros Ovalle. Manual de antropometría criminal i jeneral, Imprenta de Enrique Blanchard-Chessi, Santiago, 1900.

\section{LA FILIACIÓN ANTROPOMÉTRICA Y LOS ESPACIOS DE CASTIGO}

La antropología criminal se vio apoyada por otro recurso de identificación como fue la filiación antropométrica, desarrollada en Francia en 1879 por el médico y antropólogo Alphonse Bertillón (1853-1914) (Speckman, 99-129), quien por medio de seis o siete medidas óseas efectuadas de manera rigurosa y de acuerdo con un procedimiento establecido, logró identificar con precisión a diversos individuos. Tales mediciones fueron complementadas con un registro fotográfico, tema al que Bertillón dedicó un libro en 1890 titulado La fotografia judicial. En Francia, esta tipificación llevó a sutilezas por parte de las autoridades, fotografiándose bocas, narices, oídos, el tamaño de la frente y otros detalles, a ellos se les designó con un nombre específico para llenar correctamente la denominada ficha signalética, que reemplazó al antiguo registro que entregaba la descripción de algunas características básicas. En 1894 el doctor Pedro N. Barros Ovalle, autor de un libro acerca de la materia, había sido comisionado por el presidente de la Sociedad Médica de Chile, Augusto Orrego Luco, para estudiar dicho sistema de filiación. Tal metodología, encaminada a identificar y facilitar la tarea de policías y guardias de prisiones debía, al entender de Barros Ovalle, adaptarse a "nuestras leyes, a nuestras costumbres i nuestras necesidades", siendo preciso considerar que: 
En Chile, no tenemos sino mui defectuosamente, casi en ciernes, implantado el sistema de filiación, descripción i fotografía de los delincuentes [se dice en 1898]. La Penitenciaría de Santiago, la de Talca i la Cárcel de Valparaíso, según creo, son los pocos establecimientos penales en que se consignan datos escritos sobre filiación y caracterización de reos sentenciados. Se hace esto por medio de libros o estados, cuyos datos dejan mucho que desear, i se acumula así un material que es mui difícil de aprovechar para la identificación de los criminales, en los casos en que estos, de motu propio, no faciliten la tarea (Beca, 20).

Para la época en que Barros Ovalle publicó su Manual en 1900, la Dirección General de Prisiones y la Dirección General del Servicio de Policía habían hecho esfuerzos por incorporar el bertillonage, destacándose en esta tarea algunas personalidades como las especificadas:

El jermen existe, o más bien dicho, el sistema ya se practica en la Sección de Seguridad de esta capital, gracias al entusiasmo i espíritu progresista del ex Intendente Juan de Dios Correa S., i del esperimentado i práctico Jefe de la Sección de Seguridad don Exequiel Rodríguez. En efecto, a mediados del año próximo pasado, el señor Rodríguez, sabedor de los trabajos que veía practicando desde hace algunos años, me encargó de la instrucción del personal de la Sección i de la instalación de la fotografía judicial de los delincuentes. De acuerdo con el señor Correa Sanfuentes, este mandatario suministró los fondos necesarios para hacer las fichas de las filiaciones en número de algunos miles, imprimir dos grandes libros copiadores, hacer dos grandes cuadros al lápiz, comprar un buen número de obras, etc., i se comenzó a distribuir en el casillero alfabético 216 filiaciones verificadas el año 1895 en el presidio de esta ciudad (Barros Ovalle, XIV-XV).

El bertillonage estaba dirigido fundamentalmente a los agentes de policía de la sección de pesquisas, a los empleados de las prisiones, a los oficiales y a las tropas de la Policía del Orden y Seguridad; en el entendido que el personal de la policía, del carácter que fuese, debía poseer los conocimientos necesarios para reconocer y detener a los criminales. Pero los gabinetes de identificación que seguían la propuesta de Bertillón fueron paulatinamente incorporando otro método complementario basado en las huellas dactilares (dactiloscopía), el que fue traído a Chile por el exsecretario de la prefectura de la policía de Santiago, Luis Manuel Rodríguez, en 1903. Rodríguez vio la aplicación de dicho método en la provincia de La Plata, gracias al esfuerzo de Juan Vucetich. Fue tanto el interés que en 1905 se firmó un convenio que establecía el canje de fichas dactiloscópicas entre las policías de ambos países (Almandos, 115-124). Ello permitió una identificación menos discriminatoria, pues no reproducía un estereotipo físico.

No obstante, junto a los progresos también se encontraban las herencias del pasado. Aunque diversos esfuerzos se habían hecho, todavía para fines del siglo XIX la realidad carcelaria no era muy diferente a la de las décadas anteriores, ello afectaba 
cualquier intento por sistematizar la información respecto de los delincuentes. El abogado penalista Robustiano Vera fue muy crítico de la administración de justicia, de los procedimientos penales y del estado de los recintos penales; cuestionando incluso el tema de la educación dentro de ellos, pilar regenerativo de conductas como había sido sustentado tiempo atrás cuando se había incorporado el régimen penitenciario en Chile (León León, 2003):

Muchos han demostrado que la ignorancia no es una causa de la criminalidad, como lo creen la generalidad de las personas. Así lo aseguran Guenerey Dangeville, Morogne i Michel.

Garófalo piensa que mas puede la miseria; pero Lombroso va mas adelante y sostiene que la instrucción es una de las causas de las reincidencias o por lo menos uno de sus factores indirectos, porque el reo en las cárceles aprende, merced al oficio o al estudio, a delinquir con menor peligro y mas ventaja.

La instrucción intelectual no es un elemento de moralidad, no es mas que una fuerza que se debe infundir lo mas posible en cada clase social. La educación es ineficaz sobre las naturalezas ingenitamente perversas y solo útil en las naturalezas medias (Vera, 93-110).

El problema no se resolvía con una nueva legislación, como el Código Penal (1874), ni tampoco con crear o refaccionar las cárceles existentes, pues todavía para 1908 se escuchaban lamentos relativos a un tema que debería haber encontrado solución mucho antes:

...en Chile donde la criminalidad es tanta, donde el hecho delictuoso se viste de formas tan diversas y asombra al mundo entero por su repetición, es donde debiera establecerse pronto un laboratorio semejante, con cuyo veredicto científico se aplicaría a los delincuentes los remedios que su mal precise.

Debemos empezar por la reforma completa de nuestro sistema carcelario que, más que medio represivo y moralizador, sirve de escuela para el cometimiento de nuevos crímenes, hábilmente estudiados y discutidos en congreso de criminales (Villalón Ogass, 18).

El pensamiento criminológico positivista fue, en gran medida, una respuesta a la tensión que había mantenido el pensamiento liberal entre la evidente desigualdad en el acceso a los bienes, para satisfacer las necesidades materiales, y la violación de la ley, que representaba el delito, definido como un acto voluntario con el propósito de satisfacer dichas necesidades. A partir de la división entre hombres delincuentes y normales, las desigualdades sociales se convertían en desigualdades naturales, debido a las condiciones biológicas y psicológicas (Lombroso-Ferrera, XIV-XV). La precariedad y deterioro de las condiciones de vida de las clases pobres, en especial la obrera, condujo a los criminólogos, mediante la elaboración de estadísticas, a concluir que las conductas delictivas eran una característica inherente a ellas. La asociación 
entre miseria y criminalidad se hizo parte fundamental de las explicaciones, a la vez que los criminólogos sostenían que sus conclusiones no se derivaban de teorías abstractas, sino del estudio minucioso y demostrable de sus resultados. Así se ensayaba una explicación "científica" referente a la naturaleza del delincuente y respecto del deber que tenía la sociedad de castigarlo, además de proponerse medidas para rehabilitarlo y reincorporarlo a la sociedad, en aquellos casos en que no se tratara de un criminal nato o sin remedio. Por ello, un método científico de identificación y clasificación era esencial para demostrar tales afirmaciones y sostener que estos estudios estaban fundados en la objetividad y en las exigencias propias de cualquier ciencia.

Este conjunto de planteamientos fueron asumidos por juristas, médicos y autoridades policiales, impregnando los discursos y diagnósticos de los contemporáneos. Como ejemplo de su circulación, puede citarse una publicación referida al tema del bandidaje en la zona central de Chile. El autor, un exjefe policial, indicaba sin ningún inconveniente que el "bandido pierde todo ideal de conmiseración $\mathrm{i}$ su corazón se convierte en un muro de granito contra el cual se estrella todo sentimiento noble. El jermen del bien ha muerto en un principio porque ha sido ahogado por el jermen del mal". Qué más se podría agregar cuando después se les caracterizaba como fieras, tal como al bandido Exequiel Gutiérrez, de quien se decía:

Tarde i Lombroso, estas dos lumbreras de la fisiología criminal, tal vez habrían creído encontrar en Gutiérrez uno de aquellos seres en que no entra casi para nada la inteligencia que debiera i medita en los resultados que produce el mal, sino el impulso instintivo de la fiera, que busca sus medios de subsistencia entre los horrores de la destrucción (Pascual, 38).

La identificación a partir de las fotografías permitió, en el caso de los criminales, no solo establecer un retrato de su imagen física, sino también de su naturaleza interior, marcada por los vicios y evidenciable por un proceso degenerativo que se traducía en diversas características morfológicas que respaldaban en el medio chileno las ideas sostenidas por Lombroso en el viejo continente. En tal sentido, las imágenes y los estereotipos del desorden encontraron un vínculo estrecho en este renovado saber criminológico que permitió reforzar los discursos de las autoridades acerca de la necesidad de establecer una política de defensa social, la que se construyó sobre la exclusión de los pobres y la estigmatización de su apariencia y conductas. En tal perspectiva, se entiende que las ideas de Lombroso y Bertillón encontrasen acogida en Chile y marcaran los criterios policiales, jurídicos y penales de fines del siglo XIX y de principios del nuevo siglo. 


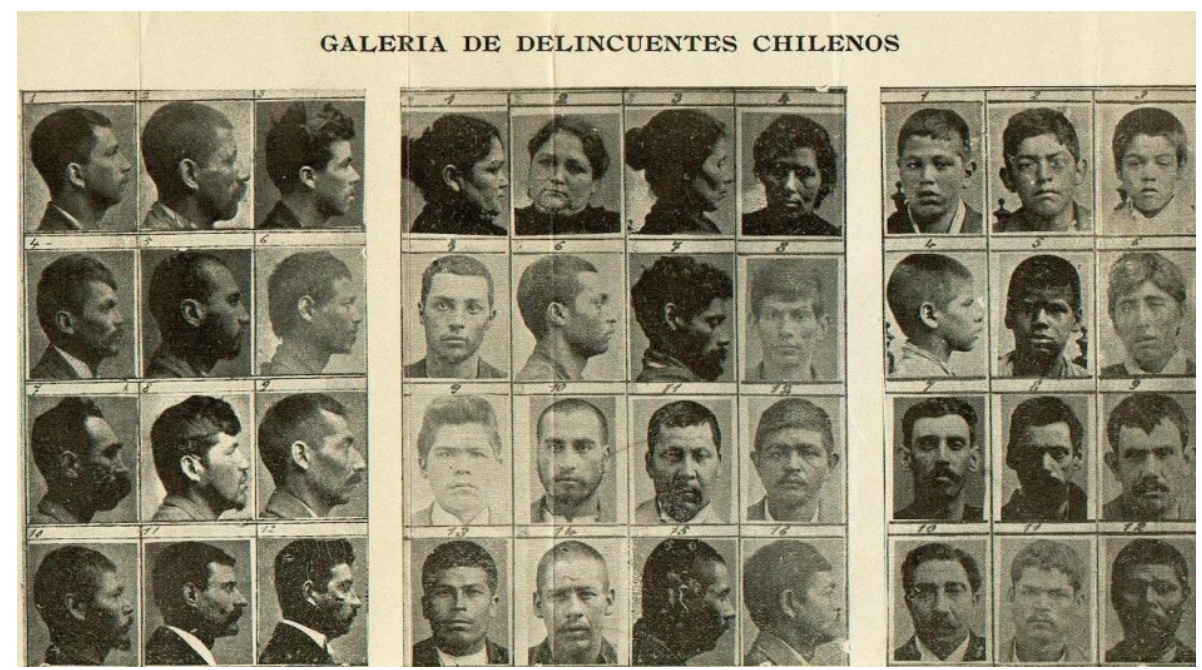

Figura 2. Galería de delincuentes chilenos, reproducida de Pedro N. Barros Ovalle. Manual de antropometría criminal i jeneral, Imprenta de Enrique Blanchard-Chessi, Santiago, 1900.

\section{CONCLUSIONES}

Sucintamente hemos tratado de mostrar cómo las ideas lombrosianas, primero, y del bertillonage, después, ayudaron a difundir y a construir en Chile una nueva idea antropológica de lo que era un criminal. Su aspecto físico, visible por medio de las mediciones antropométricas y los retratos de identificación, era el correlato obvio de una naturaleza interior vil, viciosa y criminal. En consecuencia, su identificación y caracterización apuntaba a poner en evidencia su degeneración, tanto física como moral, idea propia de un saber criminológico configurado en el viejo mundo y que fue importado sin mayores inconvenientes, pues se confiaba en su aplicabilidad mecánica a cualquier escenario histórico, geográfico y humano.

Esta nueva mirada antropológica se convirtió en una disciplina que involucró a especialistas y profanos, traspasando así los ámbitos especializados, pero no logró tener un respaldo por quienes sí se dedicaban a los estudios antropológicos en el país, debido, de acuerdo con lo que hemos podido indagar, a que sus objetos de estudio no se encontraban definidos por la contingencia, sino más bien se ubicaban en el pasado indígena. A diferencia de dicha perspectiva, la antropología criminal tuvo un interés directo en lo contingente, reafirmando bajo criterios "científicos" antiguos prejuicios de corte racista y clasista. De ahí que al momento de tomar acciones concretas respecto de la criminalidad y sus protagonistas, se volvieran a repetir dichas estigmatizaciones, aunque ahora orientando una política de defensa social que establecía límites entre lo normal y lo anormal, entre los ciudadanos y un enemigo común que habitaba en las ciudades y que era definible por su caracterización física y por la deducción de un perfil de moralidad a partir de ella. Así se podía reconocer a 
delincuentes y criminales y proyectar medidas a corto, mediano y largo plazo, pero tal manera de concebir al mundo del crimen y a sus protagonistas encontrará matices en las primeras décadas del nuevo siglo XX, cuando aparezcan algunos estudios que se alejen del determinismo biológico y tome más fuerza la dactiloscopia en reemplazo de la filiación antropométrica. No obstante, el perfil antropológico trazado desde fines del siglo anterior continuará reapareciendo intermitentemente en las décadas siguientes cada vez que sea preciso respaldar con antecedentes "científicos" prejuicios hacia una determinada clase, raza o género.

\author{
Universidad del Biobio* \\ Departamento de Ciencias Sociales \\ Campus La Castilla, Av. La Castilla sin, Chillán (Chile) \\ marcoaleon@hotmail.com
}

\title{
OBRAS CITADAS
}

Aguirre, Carlos. The Criminals of Lima and their Worlds. The Prison Experience, 1850-1935. Durham: Duke University Press, 2005.

Almandos, Luis Reyna. "Fichas palmares. Nueva aplicación de la fórmula dactiloscópica de Vucetich", en Álbum Histórico de la Policía de Chile, Santiago: Santiago Editorial, 1923: 115-124.

Anitua, Gabriel Ignacio. "Contradicciones y dificultades de las teorías del castigo en el pensamiento de la Ilustración", en Iñaki Rivera Beiras (coord.). Mitologías y discursos sobre el castigo. Barcelona: Anthropos, 2004: 13-32.

Barros Ovalle, Pedro N. Manual de antropometría criminal i jeneral. Santiago: Imprenta de Enrique Blanchard-Chessi, 1900.

Beca, Manuel Segundo. Antropolojía i Antropometría criminal. Estado de la cuestión. Estudio presentado al V Congreso Científico Jeneral Chileno de 1898. Santiago: Imprenta Cervantes, 1898.

Becker, Peter y Richard F. Wetzell (eds.). Criminals and their Scientists. The History of Criminology in Internacional Perspectives. Cambridge University Press, 2006.

Blanckaert, Claude. "Lógicas da antropotecnia: mensura do hominem e biosociología (1860-1920)", en Revista Brasileira de Historia. São Paulo, Vol. 21, № 41, 2001: 145-156.

"Des savages en pays civilis. L'anthropologie des criminels (1850-1900)", en L. Mucchielli. Histoire de la criminologie française. Paris: L'Harmattan, 1994.

Brandau, Valentín. Caracteres de la mujer según la psicología contemporánea. Santiago: S.P.I., 1908.

Buffington, Robert. Criminales y ciudadanos en el México moderno. México: Siglo XXI Editores, 2001.

“Consideraciones sobre cárceles", en Revista de Prisiones, No 1, Santiago, 1 de junio de 1889: 45-46 
Chevallier, Louis [1958]. Classes laborieuses et classes dangereuses à Paris pendant la premiére moitié du XIX siècle. Paris: Librairie Générale Française, 1978.

$\mathrm{Da}$ Re, Verónica y Sandra Maceri. "La Antropología criminal como puente entre el reduccionismo biológico y el Derecho Penal" (Primera parte), en Límite. Revista de Filosofia y Psicología. Vol. 3, № 17 y 18, Arica: Universidad de Tarapacá: 99-115; (Segunda parte), 2008: 91-108.

Del Olmo, Rosa. América Latina y su criminología, México: Siglo XXI Editores, 1981.

Fernández Labbé, Marcos. Prisión común, imaginario social e identidad. Chile, 1870-1920. Centro de Investigaciones Diego Barros Arana, Santiago: Editorial Andrés Bello, 2003.

Herman, Arthur. La idea de decadencia en la historia occidental. Santiago: Editorial Andrés Bello, 1998.

Horcasitas, Beatriz Urías. Indigena y criminal. Interpretaciones del derecho y la antropología en México, 1871-1921. Departamento de Historia, México: Universidad Iberoamericana, 2000.

"El determinismo biológico en México: Del darwinismo social a la sociología criminal", en Revista Mexicana de Sociología, México, Vol. 58, № 4, 1996: 99-126.

León León, Marco Antonio. Encierro y corrección. La configuración de un sistema de prisiones en Chile (1800-1911). 3 Tomos. Facultad de Ciencias Jurídicas y Sociales, Santiago: Universidad Central de Chile, 2003.

Lombroso-Ferrera, Gina. The Criminal Man. According to the Classification of Cesare Lombroso. New Jersey: Patterson Smith, 1972.

Massardo, Jaime. "Proyecto nacional y clases subalternas. Elementos de reconstrucción crítica del paisaje político chileno hacia 1910", en Manuel Loyola y Sergio Grez (Comps.), Los proyectos nacionales en el pensamiento político y social chileno del siglo XIX. Santiago: Ediciones Universidad Católica Silva Henríquez, 2002: 129-147.

Orellana Rodríguez, Mario. Historia de la Arqueología en Chile. Santiago: Bravo y Allende Editores, 1996.

Outtes, Joel. "Disciplinando la sociedad a través de la ciudad. El origen del urbanismo en Argentina y Brasil (1894-1945)", en Revista EURE, Vol. 28, $\mathrm{N}^{\mathrm{o}}$ 83, 2002: 7-29.

Pascual, Modesto Segundo. El capitán de bandoleros Juan de Dios López. Chillán: Imprenta y Encuadernación de la Librería Americana, 1903.

Peset, José Luis. Ciencia y marginación. Sobre negros, locos y criminales. Barcelona: Editorial Crítica, 1983.

Piccato, Pablo. City of Suspects. Crimen in Mexico City, 1900-1931. Duke University Press, 2001.

_ "La construcción de una perspectiva científica: miradas porfirianas a la criminalidad", en Historia Mexicana. Vol. XLVII, No 18. 1997: 133-181. 
Rivacoba y Rivacoba, Manuel. Manual de Criminología, Valparaíso: EDEVAL, 1982.

Salvatore, Ricardo y Carlos Aguirre (eds.). The Birth of the Penitentiary in Latin America. Essays on Criminology, Prison Reform and Social Control. 18301940. Austin: University of Texas, 1996.

Salvatore, Ricardo. "Criminología positivista, reforma de prisiones y la cuestión social/obrera en Argentina", en Juan Suriano (comp.), La cuestión social en Argentina, 1870-1943. Buenos Aires: Editorial La Colmena, 2000: 127-158.

Speckman Guerra, Elisa. "La identificación de criminales y los sistemas ideados por Alphonse Bertillon: discursos y prácticas (Ciudad de México, 1895-1913)", en Historia y Grafia, № 17, Universidad Iberoamericana, México: 99-129.

Vera, Robustiano. "Una ojeada sobre procedimientos penales y sobre el estado de las prisiones; lo que debe corregirse y lo que debe hacerse", en Estudios jurídicos. Imprenta de "El Correo", Santiago, 1890: 93-110.

Vergara Flores. "Libre albedrío y crimen", en Revista de Prisiones. N N $^{\circ}$ y 7 , Santiago, 1890: 354-360.

Villalón Ogass, Enrique. Estudios sobre antropología criminal. Imprenta i Encuadernación Universitaria, Santiago, 1908.

Zimmermann, Eduardo. "Racial Ideas and Social Reform: Argentina, 1890-1916", en Hispanic American HistoricalReview. Vol. 72, No 1, 1992: 23-46. 